www.jmscr.igmpublication.org

Index Copernicus Value: 79.54

ISSN (e)-2347-176x ISSN (p) 2455-0450

crossref DOI: https://dx.doi.org/10.18535/jmscr/v7i3.231

Journal Of Medical Science And Clinical Research

IGM Publication

An Official Publication of IGM Publication

\title{
Audit of Breech Deliveries at a Rural Tertiary Hospital in South Western Nigeria
}

\author{
Authors \\ Adeniyi Augustine Adebayo ${ }^{1,2^{*}}$, Adeyemo Olabisi Timothy ${ }^{1,2}$, \\ Okere Raymond Akujuobi, ${ }^{1,2}$, Adebara Idowu Oluseyi ${ }^{1,2}$, Bakare Adewunmi, ${ }^{1,2}$ \\ Awoyinka Babatunde Sunday ${ }^{1,2}$, Adewara Olumide Emmanuel ${ }^{1,2}$, \\ Ayankunle Mojisola O. ${ }^{1,2}$, Busari Olusegun Adesola ${ }^{3}$, Oni Ayobami.O². \\ ${ }^{1}$ Department of Obstetrics and Gynaecology, Afe Babalola University, Ado Ekiti, Nigeria \\ ${ }^{2}$ Department of Obstetrics and Gynaecology, Federal Teaching Hospital, Ido Ekiti, Nigeria \\ ${ }^{3}$ Department of Medicine Afe Babalola University, Ado Ekiti, Nigeria \\ *Corresponding Author \\ Adeniyi Augustine Adebayo
}

Department of Obstetrics and Gynaecology, Afe Babalola University, Ado Ekiti/Federal Teaching Hospital, Ido- Ekiti, Nigeria.

Phone number: +234 8037141492, Email: adeniyiaa@abuad.edu.ng; bayoadeniyis@gmail.com

\begin{abstract}
Background: Breech remains a topical issue in Obstetric practice mainly because of the high perinatal morbidity and mortality associated with its management. The management of term breech is controversial and varies among different clinicians even in the same institution.

Patients and Method: A retrospective study of breech deliveries at the FETH, Ido - Ekiti over a five year period. The records of all breech deliveries were collected. Information on age, parity, booking status, birth weight and management were extracted. Data were analyzed using Statistical Package for Social Sciences (SPSS) version 20.

Results: There were 2,333 deliveries during the study period of which one hundred and eighty one (181) were breech deliveries. However, one hundred and sixty-six (166) cases were available for analysis. The incidence of breech delivery was $7.8 \%$ for all gestational ages, the mean age of the patients was 30.26 \pm 5.39 years. The birth weights of most of the babies 99(56\%) were within the normal range of $2.5-3.99 \mathrm{~kg}$. The caesarean section $(C / S)$ rate was $72.9 \%$, 57\% of these were emergency. The perinatal mortality was significantly higher among the unbooked patients (9.5\% vs. 29.3\%, $p=0.018$ ) and among the babies delivered by vaginal delivery and emergency caesarean section compared to those delivered by planned caesarean section $(p=0.000)$. The perinatal mortality was also higher among the babies that were delivered before 37 weeks of gestation $(p=0.004)$.

Conclusion: The perinatal mortality was significantly higher among the babies delivered either by vaginal route or emergency caesarean section compared to those delivered by planned caesarean section and among the preterm babies. The outcomes were comparable to results from other studies including those from the urban centres.
\end{abstract}

Keywords: Breech deliveries, perinatal morbidity and mortality. 


\section{Introduction}

Breech is the commonest form of foetal malpresentation, its incidence varies inversely with gestational age, with an incidence ranging from 25 percent at 28 weeks to $3-4 \%$ at term. ${ }^{[1,2]}$ It has been demonstrated severally that, compared to cephalic presentation the foetus presenting by breech suffers greater perinatal morbidity and mortality $^{[3,4,5]}$ with perinatal mortality ranging from $5 \%$ to $11 \%$. The considerable debates that have characterized breech delivery centre around the mode of management that tends to reduce these adverse outcomes ${ }^{[6,7]}$

Vaginal breech deliveries were previously the norm, until late 1950s when it was proposed that all breech presentations should be delivered abdominally to reduce perinatal morbidity and mortality $^{[8]}$. In 1970, approximately $14 \%$ of breeches were delivered by cesarean delivery. By 1986, that rate had increased to $86 \%$. In 2003 , based on data from the National Center for Health Statistics, the rate of cesarean delivery for all breech presentations was $87.2 \%$. Most of the remaining breeches delivered vaginally were mostly second twins, foetal demises, and precipitous deliveries $^{[8]}$.

While many studies have shown no significant difference in the perinatal outcomes, the most celebrated study on breech delivery, the "Term Breech Trial" published in 2000, clearly demonstrated a significant reduction in the perinatal mortality in babies that were delivered by planned caesarean section when compared with those delivered by vaginal delivery. The study showed $75 \%$ reduction in the perinatal death in favour of Caesarean section (RR, 0.23; 95\% CI, $0.07-0.8)^{[9]}$.The outcome of this trial influenced many bodies recommending planned caesarean section for singleton foetus presenting by breech at term (ACOG 2001, RCOG 2001) ${ }^{[6]}$.

Though the implementation of these recommendations were readily noticed in the developed and urban centres, its impact has not been fully quantified in the context of developing and low resource settings, with greater aversion for caesarean section and tendency for large family ${ }^{[10]}$. The latter factor is important as caesarean section in addition to other morbidities also limits the number of pregnancy a woman can be exposed to. Thus implementation of recommendation from the Term Breech trial and other studies must consider these and other factors peculiar to the low resource setting. External Cephalic Version (ECV) which is recommended to reduce the incidence of breech and the Caesarean section rate, was initially popular in the 1960s and 1970s, but virtually disappeared after reports of foetal deaths following the procedure. Following its reintroduction in the United States in the 1980s, it became increasingly popular in the 1990s. However this practice is practically nonexistent in most developing countries ${ }^{[11]}$.

This study was designed to look at perinatal outcomes of breech delivery in a tertiary institution in a rural setting in South West Nigeria.

\section{Materials and Methods}

This retrospective study was a five year audit of breech deliveries between January 2009 and December 2013 at department of Obstetrics and Gynaecology, Federal Teaching Hospital, Ido Ekiti.

Medical records from the labour ward and postnatal registers were examined. Data obtained were entered into SPSS version 20. Categorical variables were summarized using numbers, percentages, tables and charts while mean, standard deviation and statistical tests were used for continuous variables. The level of significance (p-value) was set at less than 5\% ( $\mathrm{p} \leq 0.05)$.

\section{Results}

There were 2,333 deliveries during the study period out of which 181 were breech deliveries. However, one hundred and sixty-six (166) cases were available for analysis The breech delivery rate for all gestational ages from this study was $7.8 \%$. However the term breech delivery rate was $4.4 \%$. The overall caesarean section rate in the 
same study period was $40.5 \%$ while the caesarean section rate for breech deliveries was $72.9 \%$.

The age of the patients ranges between 18 and 45 years with average age of $30.26( \pm 5.39)$ years.

Majority of the patients, 97(58.4\%) were unbooked. The overall perinatal mortality was 17 $\%$. The perinatal mortality was significantly higher among the unbooked patients $((9.5 \%$ vs $29.3 \% \mathrm{p}=0.018)$. While the total caesarean section rate was $72.9 \%$, fifty - seven percent $(57 \%)$ of these were through emergency caesarean. The perinatal mortality was significantly higher among the babies delivered either by vaginal route or emergency caesarean section compared to those delivered by planned caesarean section $(\mathrm{p}=0.000)$. While the majority of the babies, 106 (63.9\%) were delivered at term, the perinatal mortality was higher among the babies that were delivered before 37 weeks of gestation $(\mathrm{p}=0.004)$.

Though more of the babies presenting by breech were female $88(53.0 \%)$, the sex of the babies had no significant effect on the perinatal outcome. ( $\mathrm{p}=0.948)$.

The birth weights of most of the babies 99 (56\%) were within normal range of $2.5-3.99 \mathrm{~kg}$, however, the perinatal mortality was significantly higher among the babies with low birth weight $(<2.5 \mathrm{~kg})(\mathrm{P}=0.004)$.

Primiparous women had the highest rate of breech delivery 77 (46.4\%). However, the parity has no significant effect on the perinatal outcome $(\mathrm{P}=$ 0.076)

Table 1: Age distribution of the Parturient

\begin{tabular}{|l|c|c|}
\hline AGE (Years) & FREQUENCY & PERCENTAGE (\%) \\
\hline $18-22$ & 16 & 9.6 \\
\hline $23-27$ & 33 & 19.9 \\
\hline $28-32$ & 59 & 35.5 \\
\hline $33-35$ & 33 & 19.9 \\
\hline$>35$ & 25 & 15.1 \\
\hline TOTAL & 166 & 100.0 \\
\hline
\end{tabular}

Figure 1 Mode of delivery of the breech

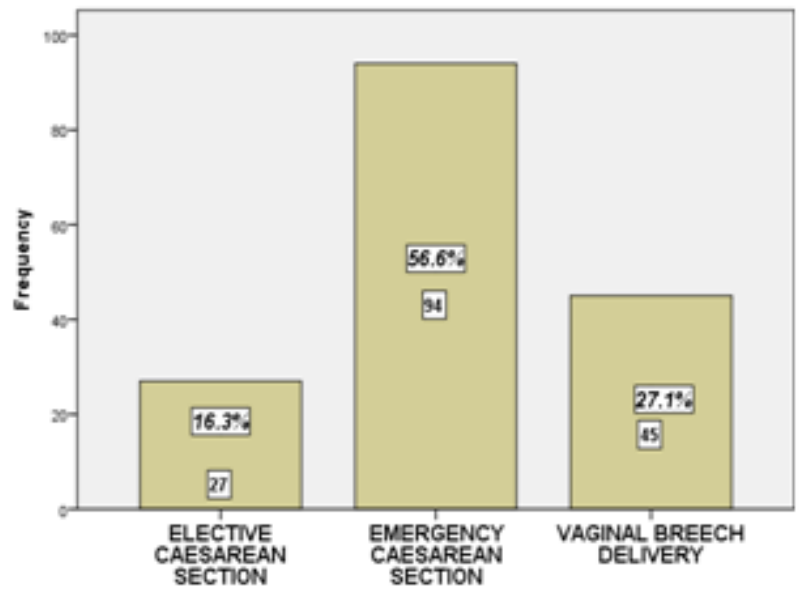

Table 2: Mode of Delivery and Outcome of Delivery

\begin{tabular}{|l|c|c|c|c|c|}
\hline Mode of delivery & \multicolumn{2}{|c|}{ Foetal Outcomes } & Total & Test $^{* *}$ & \multirow{2}{*}{ P-value } \\
\hline Elective caesarean section & Alive & Dead & & & \\
\cline { 2 - 4 } $\begin{array}{l}\text { Emergency caesarean } \\
\text { section }\end{array}$ & 27 & 0 & 27 & & \\
\cline { 2 - 5 } $\begin{array}{l}\text { Vaginal Breech Delivery } \\
\text { Total }\end{array}$ & 84 & 10 & 94 & \multirow{2}{*}{25.5} & 0.000 \\
\cline { 2 - 5 } & 27 & 18 & 45 & \\
\cline { 2 - 5 }
\end{tabular}

** Fisher's exact Test 
Table 3: Birth weight of the babies and the delivery outcome

\begin{tabular}{|c|c|c|c|c|c|}
\hline Birth weight of babies $(\mathrm{kg})$ & \multicolumn{2}{|c|}{ Foetal Outcome } & Total & Test $^{* *}$ & P-value \\
\hline \multirow[b]{2}{*}{$<1.0$} & Alive & Dead & & \multirow{8}{*}{17.4} & \multirow{8}{*}{0.004} \\
\hline & 5 & 6 & 11 & & \\
\hline $1.0-1.49$ & 9 & 3 & 12 & & \\
\hline $1.5-2.49$ & 35 & 10 & 45 & & \\
\hline $2.5-3.49$ & 65 & 7 & 72 & & \\
\hline $3.5-3.99$ & 20 & 1 & 21 & & \\
\hline$\geq 4.0$ & 4 & 1 & 5 & & \\
\hline TOTAL & 138 & 28 & 166 & & \\
\hline
\end{tabular}

\section{Discussion}

The average age of the parturient was 30.26 $( \pm 5.39)$ years. This corresponds with the findings by Adekanle et al in which most of the subjects were in the age range of 30 years and above. ${ }^{[8]}$ No significant correlation was established between maternal age and outcome in our study $(\mathrm{p}=0.310)$. Though Jolly et al ${ }^{[12]}$ reported an increased risk of breech presentation among pregnant women older than 35years, despite controlling for confounding factors such as parity. The skeletal muscle mass and tone of the myometrium which have been found to play a significant role in foetal presentation declines with maternal age. ${ }^{[13,14,15]}$

The overall incidence of breech delivery in our study was $7.8 \%$ and term rate of $4.4 \%$. The higher incidence for breech delivery when all gestational ages are considered is not unexpected as the incidence of breech presentation is much higher at lower gestational age. However, the incidence of term breech delivery in this study is higher than term rates of $2.6 \%$ from Ibadan ${ }^{16}$ and $2.84 \%$ from Nnewi. ${ }^{[3]}$

The overall caesarean section rate for breech delivery in this study was $72.9 \%$ which is comparable with reports from other studies showing an increase in the rate of caesarean section among breech presentations compared to the general delivery. Majority of the women that had breech deliveries were not booked in the health facility, the $58.4 \%$ rate found in this study is similar to the result by Adekanle et al. ${ }^{[8]}$ The clinical significance of this is that preinatal mortality was significantly higher among the unbooked patients $(9.5 \%$ vs. $29.3 \%, \mathrm{p}=0.018)$.
The commonest mode of delivery is Caesarean Section. This finding may not be unrelated to the effect of the term breech trial which has significantly skewed the decision of breech delivery toward caesarean section. ${ }^{[6,8]}$ Also, the high proportion of unbooked patients in this study may not give adequate room for counseling, planning and decision- making with some presenting in labour. ${ }^{[17]}$ In such situation the option of caesarean section with perceived lower risk to the fetus is often taken, ${ }^{[8]}$ especially where the requisite skills for vaginal delivery is lacking. However, while caesarean section may give a better foetal outcome compared to vaginal delivery, the timing of such procedure is also crucial as caesarean section performed as an emergency is associated with more morbidity than when performed as an elective procedure. This fact demonstrated in this study is similar to findings from another study. ${ }^{[18]}$ The decision on the mode of delivery of breech (vaginal versus caesarean section) is very important as it has a huge association with the outcome $(\mathrm{p}=0.001)$.

The finding of higher number of female babies in breech presentation in this study is similar to the findings of Lei Hou et al, ${ }^{[19]}$ however there was no significant difference in the foetal outcome among the male and female neonates. The male sex has been found to be associated with more labour complications such as fetal heart rate abnormalities and the need for caesarean section during induction of labour in cephalic presentation, ${ }^{[20]}$ this study did not find such discrepancy $(\mathrm{p}=0.95)$.

The significant poorer outcomes in preterm breech (gestational age $<37$ and or birth weight $<2.5 \mathrm{~kg}$ ) 
deliveries compared to term deliveries $(\mathrm{p}=0.003)$ found in this study is not unexpected as such fetuses have been noted to suffer higher morbidity resulting from entrapment of the after coming head, cord prolapse, intrapartum hypoxia and traumatic injuries. [21]

In conclusion, the incidence, management, and outcome of breech delivery in this study conducted at a rural setting compares well with what obtains from the previous studies especially in the urban settings.

\section{Sources of support: Nil}

\section{References}

1. Arulkumaran S: Malpresentation, malposition, cephalopelvic disproportion and obstetric procedures. In: Edmonds DK, editor. Dewhurst's textbook of obstetrics and gynecology. 7th ed. London: Blackwell; p. 214-2.

2. Royal College of Obstetricians and Gynaecologists, 2006. The Management of Breech Presentation Guideline No. 20b. RCOG, London, England.

3. Igwebe A.O, Mongo E.N, and Ugboaja J.O. Caesarean versus Vaginal Delivery for Term Breech Presentation: A Comparative Analysis. Afr. J. Biomed. Res. 2010; 13(1):15-18.

4. Kumari AS., Grundsell H. Mode of delivery for breech presentation in grandmultiparous women. Int J Gynaecol Obstet. 2004; 85:234-239.

5. Doyle NM, Riggs JW, Ramin SM, Sosa MA, Gilstrap LC. Outcomes of vaginal breech delivery. Am J Perinatol. 2005; 22(6):325-328.

6. Royal College of Obstetricians and Gynecologists (2001): The Management of Breech Presentation vol. 20, RCOG, London, England (April 2001) Clinical Green Top Guidelines. Available at: http://www.rcog.org.uk/index.asp?PageID $=513$.
7. Adekanle Daniel Adebode et al, Trends in Breech Delivery and Caesarean Section Rate in Low Resource Setting. World Journal of Medical Sciences. 2013; 9 (3): 123-127, 2013 ISSN 1817-3055.

8. Herbest, A. Term breech delivery in Sweden: mortality relative to fetal presentation and planned mode of delivery. Acta Obstet Gynecol Scand. 2005; 84: 593-601

9. Hannah, M.A.; Hannah, W.J.; Hewson, S.A.; Hodnett, E.D.; Saigal, S.; Willan, A.R. Planned caesarian section versus planned vaginal birth for breech presentation at term: a randomized multicentre trial. The Lancet. 2000; 356(9239): 1375-1383.

10. Orji EO, Ajenifuja KO. Planned vaginal delivery versus Caesarean section for breech presentation in Ile - Ife, Nigeria. East Afr Med J. 2003; 80(11):589-591.

11. Onah HE, Nkwo PO. External Cephalic version: a survey of current practice among Nigerian Obstetrician. Trop J Obstet Gynaecol 2004;21(1):24-26.

12. Jolly M, Sebire N, Harris J, Robinson S, Regan L. The risks associated with pregnancy in women aged35 years or older. Hum Rep 2000;15(11):2433-24332437.

13. Rosenthal, AN, Patterson Brown S. Is there an incremental rise in the risk of obstetric intervention with increasing maternal age? Br. J. Obstet. Gynaecol., 105, 1064- 1069.

14. Mehrnaz V, Fatemh DT, Azam S. Pregnancy outcomes in women of Advanced Age. J Fam. Repr.Health. 5(2);57-61.

15. Hurley BF. Age, gender, and muscular strength. J Gerontol A Biol Sci Med Sci 1995;50:41-44

16. Fawole AO, Adeyemi AS, Adewole IF, Omigbodun AO. A ten-year review of 
breech deliveries at Ibadan. Afr J Med M Sci. 2001; 30(1-2):87-90.

17. The Royal Australian and New Zealand College of Obstetrician and Gynaecologist. C-Obs, March, 2016.

18. Soukayna Benzouina, Mohammed Elmahdi Boubkraoui and Amina Barkat. Fetal outcome in emergency versus elective cesarean sections at Souissi Maternity Hospital, Morocco. PanAfrMed J. 2016; 23:197

19. Lei Hou, Xin Wang, Guuanghui Li, Liying Zou, Yi Chen, Weiyuan Zhan. Cross sectional study in China: fetal gender has adverse perinanal outcomes in mainland China. BMC Pregnancy and Childbirth. 2014; 14:372.

20. Agarwal U, Anastasaki E, Kadir RA. The effect of foetal sex on the outcome of labour induction. J.Obstet Gynaecol. 2009; 29(8): 711-3.

21. Turki G. Gasim. Preterm Singleton Breech Delivery in a Teaching Hospital of Saudi Arabia: Vaginal versus Caesarean Delivery. J Family Community Med. 2008; 15(2): 65-70. 